isoelectric focusing. Proc Natl Acad Sci USA 77:2646-2650

17. Ikeda Y, Dabrowski C, Tanaka K 1983 Separation and properties of 5 distinc acyl-CoA dehydrogenases from rat liver mitochondria: Identification of a new 2-methyl branched chain acyl-CoA dehydrogenase. J Biol Chem 258:1066-1076

18. Hall CL, Kamin H 1975 The purification and some properties of electron transfer flavoprotein and general fatty acyl coenzyme A dehydrogenase from pig liver mitochondria. J Biol Chem 250:3476-3486

19. Coates PM, Hale DE, Stanley CA, Corkey BE, Cortner JA 1984 Genetic deficiency of medium-chain acyl coenzyme A dehydrogenase: studies in cultured skin fibroblasts and peripheral mononuclear leukocytes. Pediatr Res 19:671-676

20. Stanley CA, Hale DE, Whiteman DEH, Coates PM, Yudkoff M, Berry GT, Segal S 1983 Systemic carnitine deficiency in isovaleric acidemia. Pediat Res 17:296A(abstr)

21. Roe CR, Bohan TP 1982 L-carnitine therapy in propionicacidemia. Lancet 1:1411-1412

22. Allen RJ, Hansch DB, Wu HLC 1982 Hypocarnitinaemia in disorders of organic acid metabolism. Lancet 2:500-50 1

23. Roe CR, Millington DS, Maltby DA, Bohan TP, Hoppel CL 1984 L-Carnitine enhances excretion of propionyl Coenzyme $A$ as propionylcarnitine in propionic acidemia. J Clin Invest 73:1785-1788

24. Roe CR, Millington DS, Maltby DA, Bohan TP, Kahler SG, Chalbers RA 1985 Diagnostic and therapeutic implications of medium-chain acyl carnitines in the medium-chain acyl-CoA dehydrogenase deficiency. Pediatr Res (in press)

25. Truscott RJW, Hick L, Pullin C, Halpern B, Wilcken B, Griffiths H, Silink M, Kilham H, Grunseit F 1979 Dicarboxylic aciduria: the response to fasting. Clin Chim Acta 94:31-39

26. Gregersen N, Rosleff F, Kølvraa S, Hobolth N, Rasmussen K, Lauritzen R 1980 Nonketotic $\mathrm{C}_{6}-\mathrm{C}_{10}$ dicarboxylic aciduria: Biochemical investigations of two cases. Clin Chim Acta 102:179-189

27. Gregersen N, Kølvraa S, Rasmussen K, Mortensen PB, Divry P, David M Hobolth N 1983 General (medium-chain) acyl-CoA dehydrogenase deficiency (non-ketotic dicarboxylic aciduria): quantitative urinary excretion pattern of 23 biologically significant organic acids in three cases. Clin Chim Acta 132:181-187

28. Tager JM, Wanders RJA, Groen AK, Kunz W, Bohnensack R, Kuster U, Letko G, Bohme G, Duszynski J, Wojtczak L 1983 Control of mitochondrial respiration. FEBS Lett 151:1-9

\title{
Genetic Deficiency of Medium-Chain Acyl Coenzyme A Dehydrogenase: Studies in Cultured Skin Fibroblasts and Peripheral Mononuclear Leukocytes
}

\author{
PAUl M. COATES, DANIEl E. HALE, CHARLES A. STANLEY, BARBARA E. CORKEY, AND \\ JEAN A. CORTNER \\ Departments of Pediatrics [P.M.C., D.E.H., C.A.S., J.A.C.] and Biochemistry and Biophysics [B.E.C.], University \\ of Pennsylvania School of Medicine, and Divisions of Endocrinology/Diabetes [D.E.H., C.A.S.] and Genetics \\ [P.M.C., J.A.C.], The Children's Hospital of Philadelphia, Philadelphia, Pennsylvania 19104
}

\begin{abstract}
Medium-chain acyl coenzyme A (CoA) dehydrogenase deficiency was demonstrated in fibroblasts and/or mononuclear leukocytes from 14 patients, most of whom initially presented early in childhood with a Reyelike syndrome associated with hypoketotic hypoglycemia, dicarboxylic aciduria, and low levels of plasma carnitine. Parents of these patients had intermediate levels of medium-chain acyl $\mathrm{CoA}$ dehydrogenase activity, consistent with their being heterozygous for an autosomal recessive trait. All patients had normal levels of long-chain acyl CoA dehydrogenase activity, but had reduced short-chain acyl CoA dehydrogenase activity. Fatty acid oxidation was examined in cultured fibroblasts from five of the patients, using a series of ${ }^{14} \mathrm{C}$-labeled fatty acids of different chain length (palmitic, octanoic, and butyric). Oxidation of $\left[1-^{14} \mathrm{C}\right.$-octanoic acid was less than $20 \%$ of control levels: $\left[1-{ }^{14} \mathrm{C}\right],\left[6-{ }^{14} \mathrm{C}\right]-,\left[16{ }^{14} \mathrm{C}\right]-$, and $\left[{ }^{14} \mathrm{C}(\mathrm{U})\right]-$ palmitic acid oxidation rates were $88,51,13$, and $42 \%$ of control rates,
\end{abstract}

Received November 21, 1984; accepted February 27, 1985

Address for reprints Paul M. Coates, Ph.D., Joseph Stokes, Jr. Research Institute, The Children's Hospital of Philadelphia, 34th and Civic Center Boulevard, Philadelphia, PA 19104

Supported by NIH Grants NS17752, AMO7314, AMO1226, and RR-00240, a grant from the National Reye's Syndrome Foundation of Bryan, $\mathrm{OH}$, and a grant from the W. W. Smith Charitable Trust. respectively. $\left[1-{ }^{14} \mathrm{C}\right]$-butyric acid was oxidized normally. These data extend our previous findings of medium-chain acyl $\mathrm{CoA}$ dehydrogenase deficiency in liver tissue from three of these patients. They demonstrate the value of cultured fibroblasts and leukocytes in the diagnosis and evaluation of inherited disorders of fatty acid oxidation. (Pediatr Res 19: 671-676, 1985)

\section{Abbreviations}

CoA, coenzyme A

ETF, electron transfer flavoprotein

We recently reported three patients with a defect in ketogenesis due to deficiency of hepatic medium-chain acyl CoA dehydrogenase activity (1). The three affected patients presented with a syndrome of fasting intolerance, recurrent life-threatening episodes of hypoglycemic coma, a failure of ketogenesis, low plasma and tissue carnitine levels, and medium-chain dicarboxylic aciduria. This inherited metabolic disorder has also been demonstrated in cultured fibroblasts from patients with a similar phenotype by other investigators (2-4). 
The present study was undertaken in order to evaluate medium-chain acyl CoA dehydrogenase deficiency in fibroblasts and leukocytes from 14 patients (including the three described in Ref. 1), using a modification of the fluorometric assay of acyl CoA dehydrogenases which we have previously reported. Included in this series are three patients originally described as having systemic carnitine deficiency $(5-7)$; we reported briefly on the medium-chain acyl CoA dehydrogenase deficiency in one of them (8). Our data show that their enzyme defect can be readily detected in fibroblasts and leukocytes, in agreement with previous findings obtained using liver specimens from three of these patients (1). Functional studies of fatty acid oxidation in their fibroblasts yielded results which were consistent with the location of this inherited enzyme defect. The measurement of acyl CoA dehydrogenase activities in leukocytes and fibroblasts provides a technique for rapid diagnosis of this enzyme deficiency in patients suspected of having a disorder in fatty acid oxidation. Parents of these patients, who are obligate heterozygotes for this autosomal recessive disorder, had intermediate levels of mediumchain acyl CoA dehydrogenase activity. The clinical features seen in these 12 patients, including one who is now $18 \mathrm{yr}$ old, indicate that medium-chain acyl CoA dehydrogenase deficiency can be distinguished from other disorders which present in a similar fashion, and that the disorder has a good prognosis once the defect has been recognized and appropriately managed.

Portions of this work have been published elsewhere (8).

\section{PATIENTS}

T-1, an 18-yr-old girl, has been followed at The Children's Hospital of Philadelphia since 5 yr of age for recurrent episodes of illness precipitated by fasting and characterized by severe lethargy and vomiting. The first episode occurred at 13 months of age and then, beginning at $4 \mathrm{yr}$ of age, episodes occurred nearly monthly for 6 months. On each occasion, she was hospitalized and improved within several hours after intravenous infusions of fluid and dextrose were begun. On most occasions, she was not hypoglycemic. At age $5 \mathrm{yr}$, she was admitted to The Children's Hospital of Philadelphia following one of these epi- sodes of illness. She had been well on awakening that morning, but did not eat breakfast. She became weak and lethargic and began to vomit. On admission, she was afebrile, but very limp, listless, and appeared moderately dehydrated. The liver was not enlarged, and the remainder of the physical examination was normal. Laboratory studies revealed: glucose $46 \mathrm{mg} / \mathrm{dl}$, blood urea nitrogen $21 \mathrm{mg} / \mathrm{dl}$, sodium $137 \mathrm{mEq} /$ liter, potassium 4.1 $\mathrm{mEq} /$ liter, chloride $100 \mathrm{mEq} / \mathrm{liter}$, bicarbonate $23 \mathrm{mEq} / \mathrm{liter}$, and SGOT $32 \mathrm{U} / \mathrm{ml}$.

It was initially thought that she had ketotic hypoglycemia, but a study of fasting adaptation showed evidence of defective hepatic ketone body synthesis. During this fast, she developed characteristic symptoms of lethargy and vomiting after $16 \mathrm{~h}$. At this time, her plasma glucose level was still normal $(60 \mathrm{mg} / \mathrm{dl})$, but plasma free fatty acid levels had risen markedly to $4.1 \mathrm{mmol} /$ liter. Despite the elevated levels of free fatty acids, plasma $\beta$ hydroxybutyrate levels remained low $(0.32 \mathrm{mmol} / \mathrm{liter})$. Plasma alanine and triglyceride levels were not elevated. Plasma ketone body levels did not increase after oral ingestion of medium-chain triglyceride oil $(1 \mathrm{ml} / \mathrm{kg})$. Plasma total carnitine was $19-25 \mu \mathrm{mol} /$ liter (normal $40-60 \mu \mathrm{mol} / \mathrm{liter}$ ). Liver total carnitine was 400 $\mathrm{nmol} / \mathrm{g}$ (normal $730-1800 \mathrm{nmol} / \mathrm{g}$ ).

Following the recognition that her illness was precipitated by fasts of more than 12-16 h, the patient's parents were instructed to avoid prolonged periods without feeding. This has successfully prevented all but rare recurrences of her illness. At age $18 \mathrm{yr}$, she appears normal physically and intellectually. She has no evidence of muscle weakness. She had a recent recurrence of her illness when she "forgot" to eat breakfast, but fully recovered in $2 \mathrm{~h}$ with intravenous infusion of $10 \%$ dextrose. Shortly after this episode, studies were carried out in her skin fibroblasts.

Table 1 provides a brief summary of the clinical and laboratory findings in five patients (F-1, N-1, S-1, W-1, and Z-1) seen at The Children's Hospital of Philadelphia, two patients whose cells were sent to us for study (H-1 and K-1) by Drs. Rosalind Coleman and Charles Roe at Duke University, and three patients who had been reported as having systemic carnitine deficiency, patient 12 (Ref. 5; patient A in Ref. 7) and patients 13 and 14 (Ref. 6; patients C and D in Ref. 7). They are compared to the

Table 1. Clinical and laboratory findings in 14 patients with medium-chain acyl CoA dehydrogenase deficiency

\begin{tabular}{|c|c|c|c|c|c|c|c|c|c|c|c|}
\hline \multirow[b]{2}{*}{ Patient } & \multirow[b]{2}{*}{ Sex } & \multicolumn{2}{|c|}{ Age (yr) } & \multirow[b]{2}{*}{ Reye* } & \multirow[b]{2}{*}{ DCA $\dagger$} & \multirow[b]{2}{*}{ Carnitine } & \multirow[b]{2}{*}{ Recurrences } & \multirow[b]{2}{*}{ Sib death } & \multicolumn{2}{|c|}{ MC-ACD $\$$} & \multirow[b]{2}{*}{ Notes } \\
\hline & & 1st episode & Current & & & & & & FB & ML & \\
\hline B-1 & $\mathrm{F}$ & $6 / 12$ & - & + & NT\| & NT & 1 & 0 & 0.34 & - & Ref. 1 \\
\hline B-2 & $\mathrm{M}$ & $23 / 12$ & 12 & - & + & 18 & 0 & 1 & 0.34 & - & $\begin{array}{l}\text { Sibling of B-1; } \\
\text { Ref. } 1\end{array}$ \\
\hline F-1 & $\mathbf{M}$ & $6 / 12$ & $16 / 12$ & + & + & 17 & 2 & 0 & 0.41 & 0.34 & \\
\hline M-1 & $F$ & $11 / 12$ & 5 & - & + & 7 & 2 & 0 & 0.34 & - & Ref. 1 \\
\hline $\mathrm{N}-1$ & $\mathrm{~F}$ & $6 / 12$ & $16 / 12$ & + & + & 22 & 2 & 1 & 0.49 & - & \\
\hline S-1 & $\mathbf{M}$ & $5 / 12$ & $12 / 12$ & - & + & 11 & 2 & 0 & - & 0.40 & \\
\hline $\mathrm{T}-1$ & $F$ & $11 / 12$ & 18 & - & NT & 19 & $>10$ & 0 & 0.27 & - & See case report \\
\hline $\mathrm{W}-1$ & $\mathbf{M}$ & $6 / 12$ & 1 & + & + & 12 & 2 & 0 & 0.47 & 0.48 & \\
\hline$Z-1$ & $F$ & $16 / 12$ & $26 / 12$ & + & + & NT & 1 & 2 & - & 0.28 & \\
\hline $\mathrm{H}-1$ & $\mathbf{F}$ & $11 / 12$ & 3 & + & + & 13 & 0 & 1 & 0.22 & - & Data from Ref. 15 \\
\hline $\mathrm{K}-1$ & $\mathrm{~F}$ & $7 / 12$ & 3 & - & + & 34 & 2 & 0 & 0.29 & - & Data from Ref. 15 \\
\hline 12 & $\mathrm{~F}$ & $11 / 12$ & 9 & + & + & 26 & 2 & 0 & 0.31 & - & $\begin{array}{l}\text { Data from Ref. } 5 \text {, } \\
\quad 7,8\end{array}$ \\
\hline 13 & $\mathrm{~F}$ & $11 / 12$ & 12 & + & NRT & 26 & 1 & 0 & - & 0.37 & $\begin{array}{l}\text { Data from Ref. } 6 \text {, } \\
7\end{array}$ \\
\hline 14 & $\mathrm{~F}$ & - & 14 & - & NR & 8 & 0 & 0 & - & 0.37 & $\begin{array}{l}\text { Sibling of 13; data } \\
\text { from Ref. } 6,7\end{array}$ \\
\hline
\end{tabular}

* Diagnosis of Reye syndrome made or strongly considered initially.

† Dicarboxylic aciduria, increased suberic, sebacic and adipic acids with low $\beta$-hydroxybutyrate during illness or fasting.

$¥$ Plasma total carnitine in nonfasted state ( $\mu \mathrm{mol} / \mathrm{liter})$; normal $40-60$.

$\S$ Medium-chain acyl CoA dehydrogenase activity (nmol ETF reduced $/ \mathrm{min} / \mathrm{mg}$ protein) in fibroblasts (FB) and mononuclear leukocytes (ML); normal range 3.10-5.12 (FB) and 3.66-5.09 (ML); see text for details.

$\|$ Not tested.

II Not reported. 
findings in $\mathrm{T}-1$ and in our three previously reported patients (B-1, B-2, and M-1).

\section{MATERIALS AND METHODS}

Fibroblast culture. Skin biopsies were taken from patients B-1, B-2, H-1, F-1, K-1, M-1, N-1, T-1, and W-1 after obtaining informed consent from their parents. Detailed clinical and laboratory findings in patients B-1, B-2, and M-1 have been reported elsewhere (1). Fibroblast cultures from patient 12 were from the Human Genetic Mutant Cell Repository (GM 4488). Fibroblast cultures were also available from six parents of these patients (B-3, M-2, M-3, H-2, H-3, K-2) and from an unaffected sibling of B-1 (B-4). Cultures of control lines were obtained from the Human Genetic Mutant Cell Repository, Institute for Medical Research, Camden, NJ (GM10, GM38, GM41, GM5565, GM5659) and from the Cell Center of the Human Genetics Center, University of Pennsylvania. Cells between the 4th and 15 th passages were used for the studies described herein. Fibroblast cultures were grown in RPMI 1640 medium supplemented with $10 \%$ fetal bovine serum. Monolayers were harvested by trypsinization and washed with RPMI 1640 medium.

Fibroblast cultures of the following patients are available from the Human Genetic Mutant Cell Repository: B-1, GM5870; M-1, GM5872; T-1, GM6125; B-3, GM6126.

Isolation of leukocytes. Mononuclear leukocytes were isolated from six patients (F-1, S-1, W-1, Z-1, and patients 13 and 14), seven of their available parents (F-2, F-3, S-2, S-3, W-2, Z-2, Z3 ), and one unaffected sibling (Z-4) by the method previously described by Coates et al. (9). Briefly, heparinized blood was diluted 1:1 with Hanks' balanced salt solution $(\mathrm{pH} 7.2)$ and layered over Ficoll-Paque (Pharmacia) in siliconized glass centrifuge tubes. Tubes were centrifuged for $40 \mathrm{~min}$ at $400 \times \mathrm{g}$ at room temperature. Mononuclear leukocyte rings were isolated, transferred to clear siliconized glass tubes, and washed in Hanks' solution. Contaminating erythrocytes were removed by hypotonic lysis. To a pellet of cells, $1 \mathrm{ml}$ of water was added, the cells were resuspended, and placed on ice for $30 \mathrm{~s}$. Then, $1 \mathrm{ml}$ of $0.3 \mathrm{M} \mathrm{NaCl}$ was added; cells were mixed well and centrifuged at $400 \times g$ for $10 \mathrm{~min}$. The supernatant was decanted and this procedure was repeated until the pellet was free of erythrocytes. Usually one further wash was sufficient.

Acyl CoA dehydrogenase assay in fibroblasts and mononuclear leukocytes. Cell pellets of fibroblasts and mononuclear leukocytes were frozen at $-20^{\circ} \mathrm{C}$ until they were used for enzyme assay. Cells were homogenized by sonication for $30 \mathrm{~s}$ at $30 \mathrm{~W}$ on ice in $25 \mathrm{mM}$ potassium phosphate buffer, $\mathrm{pH} 7.4$, containing $0.2 \mathrm{mM}$ EDTA, before centrifugation at $40,000 \times g$ for $30 \mathrm{~min}$ at $4^{\circ} \mathrm{C}$. The supernatant, containing $2-5 \mathrm{mg}$ protein per milliliter, was kept on ice and used for assay the same day. Frozen cell pellets have been kept at $-20^{\circ} \mathrm{C}$ for 4 months without loss of acyl CoA dehydrogenase activities. Supernatants kept at $4^{\circ} \mathrm{C}$ for more than 1 day or frozen at $-20^{\circ} \mathrm{C}$ for any period of time, at these protein concentrations, lose acyl $\mathrm{CoA}$ dehydrogenase activities.

The assay is essentially as described by Frerman et al. $(10,11)$. The final reaction mixture contained, in a total volume of 1.5 $\mathrm{ml}, 20 \mathrm{mM}$ Tris- $\mathrm{HCl}$ buffer, $\mathrm{pH} 8.0,18.5 \mathrm{mM}$ glucose, $2 \mu \mathrm{M}$ purified pig liver ETF, $20 \mathrm{U}$ of glucose oxidase (type V, Sigma), $0.5 \mathrm{U}$ of bovine liver catalase (Sigma), $50 \mu \mathrm{M}$ acyl CoA substrate (palmityl CoA, octanoyl CoA, butyryl CoA, isovaleryl CoA, all available from P-L Biochemicals), and 10-200 $\mu \mathrm{g}$ of supernatant protein. The mixture containing buffer, glucose, ETF, acyl CoA substrate, and catalase was placed in a sealed cuvette and made anaerobic by 10 cycles of alternate evacuation and purging with argon and was left under slight positive pressure. Glucose oxidase $(20 \mathrm{U})$ was added by syringe and the mixture was preincubated for $10 \mathrm{~min}$ at $30^{\circ} \mathrm{C}$. The reaction was initiated by the addition of cell supernatant. Assays were carried out in duplicate at three or more protein concentrations. The fluorescence of oxidized ETF flavin was monitored at excitation and emission wave- lengths of 342 and $496 \mathrm{~nm}$, respectively, using an Aminco SPF 125 spectrophotofluorometer. The decrease in fluorescence was followed as ETF became reduced. Enzyme activity was expressed as nmol ETF reduced per minute per milligram protein. In control fibroblasts and leukocytes, these assays were linear with respect to protein concentration from $5-150 \mu \mathrm{g} / \mathrm{ml}$ of reaction mixture. At low protein concentrations, the assays were linear with respect to time for about $5 \mathrm{~min}$, after which the rates declined; enzyme activities were generally measured by following the change in ETF fluorescence during the first 2-3 min after adding the enzyme source. ETF was purified from pig liver according to the method of Husain and Steenkamp (12). The ratio of absorbances at 270 and $436 \mathrm{~nm}$ for the preparation was 6.1 . The concentration of ETF was determined spectrophotometrically at $436 \mathrm{~nm}$, extinction coefficient $=13.4 \mathrm{mM}^{-1}(13)$.

Protein content was measured by the method of Lowry $e t$ al. (14), using bovine serum albumin as standard.

Fatty acid oxidation in fibroblasts. For studies of fatty acid oxidation, cells were resuspended in Krebs-Ringer bicarbonate buffer, $\mathrm{pH}$ 7.2. Cell number was adjusted so that the final incubation medium contained 2.5 to $10 \times 10^{5}$ cells per assay. Cells were incubated with fatty acids bound to albumin (Sigma bovine serum albumin, fatty acid-free, catalog A-7511) in a final volume of $3.0 \mathrm{ml}$ in polypropylene bottles (Wheaton Scientific) sealed with rubber stoppers and equipped with hanging center wells (Kontes Scientific).

The fatty acids tested, their source, and their final specific activities in incubation mixtures were as follows: $\left[1-{ }^{14} \mathrm{C}\right]-$ and $\left[{ }^{14} \mathrm{C}(\mathrm{U})\right]$-palmitic acid and $\left[1-{ }^{14} \mathrm{C}\right]$-octanoic acid (New England Nuclear, $0.3 \mathrm{mCi} / \mathrm{mmol}$ ); $\left[1-{ }^{14} \mathrm{C}\right]$-butyric acid (New England Nuclear, $1.6 \mathrm{mCi} / \mathrm{mmol}) ;\left[6-{ }^{14} \mathrm{C}\right]-$ and $\left[16-{ }^{14} \mathrm{C}\right]$-palmitic acid (Research Products International, $0.3 \mathrm{mCi} / \mathrm{mmol}$ ). The final concentration of palmitic acid and octanoic acid was $2.5 \mathrm{mM}$; butyric acid was $10 \mathrm{mM}$. Preliminary experiments revealed that these were saturating substrate concentrations. The fatty acid:bovine serum albumin molar ratio was $4: 1$.

Incubations were for $1-6 \mathrm{~h}$ at $37^{\circ} \mathrm{C}$ in a shaking water bath. Reactions were terminated by adding $1 \mathrm{ml}$ of $1 \mathrm{~N} \mathrm{H}_{2} \mathrm{SO}_{4}$ through the rubber stoppers. Hyamine hydroxide $(0.3 \mathrm{ml})$ was added to the center wells: ${ }^{14} \mathrm{CO}_{2}$ was trapped by incubating the flasks for $1 \mathrm{~h}$ at room temperature. Radioactivity was measured by liquid scintillation counting in a cocktail consisting of $80 \%$ Econofluor (New England Nuclear); $20 \%$ ethanol (vol:vol). All reactions were run in triplicate. After an initial lag period of $0.5-1 \mathrm{~h}$, oxidation rates were linear for at least $4 \mathrm{~h}$ in control cells with all substrates tested. Data were expressed as $\mathrm{nmol} \mathrm{CO}_{2}$ produced per $10^{6}$ cells per hour.

Statistical analysis of data. Results were expressed as mean \pm SD and differences between means were evaluated by Student's $t$ test.

\section{RESULTS}

Table 1 presents a brief description of each of the patients in this series. There were 10 females and four males; almost all of them had their first episode of illness before $2 \mathrm{yr}$ of age, with a mean age at onset of 11 months. All but one (B-1) are still alive and 11 have had repeated episodes. One patient (no. 14) has never reported any episodes of illness. Eight patients carried a diagnosis of Reye syndrome. Increased urinary excretion of medium-chain length dicarboxylic acids (suberic, sebacic, and adipic acids) was noted in all of those tested; they also showed no or only trace ketones in their urine at the time of these episodes. Excretion of both suberylglycine and hexanoylglycine was noted (15) in four of the patients (B-2, M-1, K-1, and $\mathrm{H}-1$ ), but was not specifically looked for in the others. Plasma total carnitine was measured in the fed state in 12 of the patients; 11 had levels well below the normal range, but one had a total carnitine level near the normal range of $40-60 \mu \mathrm{mol} / \mathrm{liter}$. A 
total of five siblings in four of the families died early in life with a disease suspiciously like that seen in the patients.

Table 1 also shows the individual results obtained by measuring medium-chain acyl CoA dehydrogenase activity with octanoyl CoA as substrate in fibroblasts from 10 of the patients and in leukocytes from six of them. Repeated assays of the same fibroblast culture (both control and patient) gave highly reproducible results, both within the same day using a single sample and between days using different cell preparations of the same culture. All patients had very low levels of medium-chain acyl CoA dehydrogenase in fibroblasts and/or leukocytes. As shown in Table 2 , the mean enzyme activity in patient fibroblasts was $9.2 \%$ of the mean activity in control cells $(p<0.01)$, and this residual activity ranged from $5.8-12.9 \%$ of control levels. The mean enzyme activity in patient leukocytes (Table 2 ) was $9.0 \%$ of the mean activity in control cells $(p<0.01)$ and the range was from $6.8-11.7 \%$ of control levels.

Table 2 summarizes the data for all three fatty acyl CoA dehydrogenase activities in fibroblasts and leukocytes from patients, their parents, and controls. Patients with medium-chain acyl CoA dehydrogenase deficiency had long-chain enzyme activity (measured with palmityl $\mathrm{CoA}$ as substrate) within the control range in both fibroblasts and leukocytes. However, their short-chain enzyme activity (measured with butyryl CoA as substrate) was significantly lower in both fibroblasts $(42.4 \%$ of control, $p<0.01$ ) and leukocytes ( $42.6 \%$ of control, $p<0.01$ ).

Fibroblasts from the parents of these patients had $44.3 \%$ of control levels of medium-chain acyl CoA dehydrogenase activity, significantly different from both control $(p<0.01)$ and patient $(p<0.01)$ fibroblast enzyme activity. The same was true in leukocytes from the parents; medium-chain acyl CoA dehydrogenase activity was $54.6 \%$ of control levels, and significantly different from both control $(p<0.01)$ and patient $(p<0.01)$ leukocyte enzyme activity. In both tissues, there was no overlap of medium-chain acyl CoA dehydrogenase activity among patients, their parents, and controls. Long-chain acyl CoA dehydrogenase activity in fibroblasts and leukocytes from the parents was within the control range, but short-chain acyl CoA dehydrogenase activity was significantly reduced in both tissues from parents when compared to controls.

Leukocytes from $Z-4$, an unaffected sibling of $Z-1$, and fibroblasts from B-4, an unaffected sibling of B-1 and B-2, had intermediate levels of medium-chain acyl CoA dehydrogenase, suggesting that they were both heterozygous for this inherited enzyme deficiency.

Isovaleryl CoA dehydrogenase activity was measured with isovaleryl CoA as substrate in fibroblasts from two patients, F-1 and $\mathrm{N}-1$; their enzyme activities, 1.76 and $2.29 \mathrm{nmol}$ ETF reduced per minute per milligram protein, respectively, were within the control range, $1.60-2.57(n=3)$.

Table 3 summarizes the rates of oxidation of a variety of labeled fatty acids in all of the fibroblast cultures tested. Patient cultures had rates of $\left[1-{ }^{14} \mathrm{C}\right]$-octanoic acid oxidation only $20 \%$ of those found in control cultures $(p<0.05)$. On the other hand, the rate of $\left[1-{ }^{14} \mathrm{C}\right]$-palmitic acid oxidation in patient cultures was similar to that in control cultures $(p>0.05)$. When $\left[1{ }^{14} \mathrm{C}\right]-$ butyric acid was used as substrate, patient and control cultures also showed similar rates of ${ }^{14} \mathrm{CO}_{2}$ production $(p>0.05)$. These data suggest that the first carbon of a long-chain fatty acid (palmitic) can be used for $\mathrm{CO}_{2}$ production by patient cells, but the first carbon of a medium-chain fatty acid (octanoic) cannot. $\beta$-Oxidation of a short-chain fatty acid (butyric) is not blocked by medium-chain acyl CoA dehydrogenase deficiency and proceeds at a normal rate.

This conclusion is strengthened by the data obtained using palmitic acid labeled with ${ }^{14} \mathrm{C}$ at different positions in the molecule, also shown in Table 3. Whereas the first carbon of palmitic acid was recovered as ${ }^{14} \mathrm{CO}_{2}$ equally well in patient and control cultures, a carbon near the middle of the molecule, i.e. $\left[6-{ }^{14} \mathrm{C}\right]$, was recovered as ${ }^{14} \mathrm{CO}_{2}$ in patient cultures at only $51 \%$ of the control rate $(p<0.05)$. The terminal carbon, $\left[16^{-14} \mathrm{C}\right]$, appeared as ${ }^{14} \mathrm{CO}_{2}$ at only $13 \%$ of the control rate $(p<0.01)$. These results indicate that cells from the patients are capable of oxidizing longchain fatty acids through the first few turns of the $\beta$-oxidation spiral, but that later steps, which depend on oxidation of the fatty acid at the level of the medium chain, are blocked. The fact that uniformly labeled palmitic acid was oxidized at $46 \%$ of the control rate in patient cells $(p<0.05)$ provides further evidence that the metabolic block is at the level of medium-chain fatty acid oxidation.

\section{DISCUSSION}

Medium-chain acyl CoA dehydrogenase deficiency has now been demonstrated in 20 patients (including those in the present report) with episodic illness resembling Reye syndrome (2-4, 16). In at least five other reported cases (17-20), clinical and laboratory findings suggest that they probably have the same enzymatic defect. One other patient (21) previously thought to have deficient medium-chain acyl CoA dehydrogenase actually has a defect in the long-chain enzyme (22). The diagnosis of medium-chain acyl CoA dehydrogenase deficiency has been made in liver $(1,16)$, cultured fibroblasts $(2-4,8)$, and now in leukocytes. Several methods have been developed for the assay of this enzyme and the related $\mathrm{CoA}$ dehydrogenases specific for

Table 2. Acyl CoA dehydrogenase activities in cultured skin fibroblasts (FB) and peripheral mononuclear leukocytes (ML) of patients and their parents*

\begin{tabular}{|c|c|c|c|c|c|c|}
\hline & \multicolumn{2}{|c|}{ Long-chain } & \multicolumn{2}{|c|}{ Medium-chain } & \multicolumn{2}{|c|}{ Short-chain } \\
\hline & FB & ML & FB & ML & FB & ML \\
\hline Patients & $2.13 \pm 0.60(9)$ & $2.03 \pm 0.25(6)$ & $0.35 \pm 0.09(10)^{a}$ & $0.37 \pm 0.07(6)^{a}$ & $0.95 \pm 0.14(6)^{a}$ & $0.89 \pm 0.15(5)^{a}$ \\
\hline Parents & $2.49 \pm 1.27(5)$ & $2.29 \pm 0.19(7)$ & $1.68 \pm 0.18(6)^{a}$ & $2.25 \pm 0.35(8)^{a}$ & $1.61 \pm 0.30(5)^{a}$ & $1.62 \pm 0.21(7)^{a}$ \\
\hline Controls & $2.24 \pm 0.26(14)$ & $2.11 \pm 0.30(15)$ & $3.79 \pm 0.57(14)^{a}$ & $4.12 \pm 0.48(14)^{a}$ & $2.24 \pm 0.22(5)^{a}$ & $2.09 \pm 0.33(13)^{a}$ \\
\hline
\end{tabular}

* Enzyme activities expressed as nmol ETF reduced $/ \mathrm{min} / \mathrm{mg} /$ protein, mean \pm SD for the number of samples shown in parentheses. Values in a column sharing the same superscript differ significantly from one another; ${ }^{a} p<0.01$.

Table 3. Fatty acid oxidation in cultured skin fibroblasts from patients and controls

\begin{tabular}{ccccccc}
\hline & \multirow{2}{*}{$\begin{array}{c}\text { Butyric* } \\
\end{array}$} & Octanoic & \multicolumn{4}{c}{ Palmitic } \\
\cline { 4 - 6 } & {$\left[1{ }^{14} \mathrm{C}\right]$} & {$\left[1-{ }^{14} \mathrm{C}\right]$} & {$\left[1-{ }^{14} \mathrm{C}\right]$} & {$\left[6-{ }^{14} \mathrm{C}\right]$} & {$\left[16-{ }^{14} \mathrm{C}\right]$} & {$\left[{ }^{14} \mathrm{C}(\mathrm{U})\right]$} \\
\hline Patients & $44.1 \pm 3.0(3)$ & $3.0 \pm 0.2(5) \dagger$ & $13.4 \pm 0.3(5)$ & $4.7 \pm 0.6(3) \dagger$ & $0.9 \pm 0.4(3) \dagger$ & $6.9 \pm 0.4(5) \dagger$ \\
Controls & $35.0 \pm 13.0(10)$ & $15.1 \pm 5.7(10)$ & $14.5 \pm 1.5(10)$ & $9.2 \pm 3.1(4)$ & $6.3 \pm 2.1(4)$ & $15.0 \pm 1.0(4)$ \\
\hline
\end{tabular}

* For each substrate, results are expressed as $\mathrm{nmol} \mathrm{CO} 2 / 10^{6}$ cells $/ \mathrm{h}$, mean $\pm \mathrm{SD}$ for the number of cultures shown in parentheses.

$\dagger$ Mean for patients significantly different from controls, $p<0.05$. 
long- and short-chain acyl CoA compounds and for isovaleryl CoA (23). Rhead and coworkers have used a dye-reduction assay linked to ETF (4) as well as a tritium release assay (24), and Kфlvraa et al. (3) have used gas chromatography-mass spectrometry techniques to demonstrate medium-chain acyl CoA dehydrogenase deficiency in cells from their patients. In the current report, we have used an assay based entirely on the transfer of electrons to the natural electron acceptor, ETF. The ETF-based assay is simple, reliable, and not subject to interference by other endogenous agents or by enzymes capable of reducing artificial electron acceptors. It is especially useful when only minute amounts of tissue are available and can be used on specimens of frozen tissue. This assay is qualitatively similar to the one which was used to demonstrate the enzyme deficiency in liver tissue from the three previously reported patients (1), but is considerably more sensitive.

Cells from patients with deficiency of medium-chain acyl CoA dehydrogenase have residual enzyme activity which is about $10 \%$ of control fibroblast or leukocyte levels. Together with data from the patients' parents, who have $50 \%$ of control levels, these results demonstrate that the enzyme deficiency is inherited as an autosomal recessive trait. There are two factors that may explain the residual enzyme activity in patient cells: the mutant enzyme may have small, but detectable, activity toward octanoyl CoA as substrate; or one of the other acyl CoA dehydrogenases, longchain or short-chain, may have slightly overlapping specificity which permits limited activity towards octanoyl CoA. Ikeda $e t$ al. (25) have partially purified these enzymes from rat liver mitochondria and have demonstrated that long-chain acyl CoA dehydrogenase does recognize octanoyl $\mathrm{CoA}$ as substrate while short-chain acyl CoA dehydrogenase does not; whether this is true for the human enzymes remains to be determined.

The results obtained from studies of fatty acid oxidation in cultured fibroblasts confirm the location of this enzyme defect in the middle of the oxidation pathway, and are consistent with the findings previously reported by Stanley et al. (1) measuring ketogenesis in liver. Rhead et al. (4), Saudubray et al. (26), and Kфlvraa et al. (3) have also demonstrated the functional effect of this enzyme deficiency in cultured fibroblasts using fatty acids of different chain length labeled in the $\left[1-{ }^{14} \mathrm{C}\right]$ position. Our data, using palmitic acid labeled at different positions in the chain, support the fact that a long-chain fatty acid (as the acyl CoA ester) can be efficiently oxidized only about half-way.

The observation (Table 2) that medium-chain acyl CoA dehydrogenase deficiency is associated with a significant reduction in the dehydrogenation of the short-chain ester, butyryl CoA, warrants further investigation. This has also been noted by Rhead et al. (4). A likely explanation is that there is sufficient overlap in substrate specificity so that the medium-chain enzyme contributes a significant portion of the activity seen with the 4carbon substrate, butyryl CoA. In any event, there was no apparent impairment in the oxidation of short-chain fatty acids (Table 3).

The clinical experience gained from the study of these patients, as well as patients described by others $(2,5,6,16,27-29)$, permits us to draw a few general conclusions about the nature of the illness associated with medium-chain acyl CoA dehydrogenase deficiency. In some patients, the disease may be severe and fatal: patient B-1 died during her second episode (1); Gregersen $e t$ al. (28) and Howat $e t$ al. (16) both reported fatal cases; and it is likely that some (if not all) of the sibling deaths in the families of our patients resulted from the same disease. For the most part, however, their episodes of illness are relatively mild and can be prevented by avoiding prolonged fasting. This was especially evident in patient $\mathrm{T}-1$ (see case report), who suffered numerous episodes before it was recognized that fasting provoked her illness. The long-term experience with this patient suggests that, while her fasting intolerance has persisted well into her second decade of life, she appears not to have developed any chronic or progressive signs of impaired fatty acid metabolism, such as skeletal muscle weakness or cardiomyopathy. This is in contrast to the more severe, catastrophic illness suffered by the majority of patients whom we have described with the closely related enzymatic defect, long-chain acyl CoA dehydrogenase deficiency; in that disorder cardiomyopathy or chronic skeletal muscle weakness are likely to be important components (22).

Since more than half of the patients in this series, as well as patients reported by others $(3,5,6,16,28)$, were initially thought to have Reye syndrome, it may be that children with mediumchain acyl CoA dehydrogenase deficiency represent a subset of those patients with the Reye syndrome phenotype. The onset of symptoms in patients with this enzyme defect often follows a viral infection, but they can also become symptomatic after prolonged fasting not necessarily associated with viral illness. Recurrences are common in this group and the age of onset of their first episode, often within the first year of life (Table 1), distinguishes them from most patients who present with Reye syndrome. Two other features may be particularly helpful in differentiating patients with medium-chain acyl CoA dehydrogenase deficiency from others who present with Reye syndrome. First, in the fasted state, patients with this enzyme deficiency have markedly increased urinary excretion of medium-chain dicarboxylic acids and Gregersen et al. $(28,30)$ and Roe et al. (15) have emphasized that these patients characteristically excrete large qualities of the glycine conjugates of medium-chain length fatty acids. Roe et al. (15) further demonstrated that they excrete octanoylcarnitine in their urine, regardless of their clinical state. Second, in the fed state, their plasma total carnitine levels are usually low; in fact, three of the patients in this series have been reported to have systemic carnitine deficiency $(5-7)$.

Our results indicate that the diagnosis of medium-chain acyl CoA dehydrogenase deficiency can be made rapidly and efficiently using peripheral mononuclear leukocytes as well as cultured fibroblasts. This diagnosis should be strongly considered in those children who present early in life with the Reye syndrome phenotype, in whom there is a family history of Reye syndrome, especially if it is recurrent, and in the presence of low carnitine levels. As techniques become available for the rapid measurement of other enzymes in the $\beta$-oxidation pathway of leukocytes and fibroblasts, it may be possible to distinguish other inherited disorders associated with fasting intolerance.

Acknowledgments. The authors are indebted to Dr. Carole Hall, Dr. Frank Frerman, and Dr. Stephen Goodman for many helpful discussions about the assay of acyl CoA dehydrogenases. We acknowledge the participation of Dr. David Finegold and Dr. Lester Baker in the management and care of patient T-1. We thank Dr. Rosalind Coleman, Dr. Charles Roe, Dr. Allen Glasgow, and Dr. Robert Cruse for their help in obtaining material from their patients. We are grateful for the technical assistance of Ms. Teresa DeAngelis, Ms. Ra-mond SpencerFaison, Mr. George Booz, Mr. Joseph Egler, Mr. Mark Katz, and Mr. James Wright in this work.

\section{REFERENCES}

1. Stanley CA, Hale DE, Coates PM, Hall CL, Corkey BE, Yang W, Kelley RI, Gonzales E, Williamson JR, Baker L 1983 Medium-chain acyl-CoA dehydrogenase deficiency in children with non-ketotic hypoglycemia and low carnitine levels. Pediatr Res 17:877-884

2. Divry P, David M, Gregersen N, K $\phi$ lvraa S, Christensen E, Collet JP, Dellamonica C, Cotte J 1983 Dicarboxylic aciduria due to medium chain acyl CoA dehydrogenase defect. A cause of hypoglycemia in childhood. Acta Pediatr Scand 72:943-949

3. Kфlvraa S, Gregersen N, Christensen E, Hobolth N 1982 In vitro fibroblast studies in a patient with $\mathrm{C}_{6}$ - $\mathrm{C}_{10}$-dicarboxylic aciduria: evidence for a defect in general acyl-CoA dehydrogenase. Clin Chim Acta 126:53-67

4. Rhead WJ, Amendt BA, Fritchman KS, Felts SJ 1983 Dicarboxylic aciduria: deficient $\left[1-{ }^{14} \mathrm{C}\right]$ octanoate oxidation and medium-chain acyl-CoA dehydrogenase in fibroblasts. Science 221:73-75

5. Glasgow AM, Eng G, Engel AG 1980 Systemic carnitine deficiency simulating recurrent Reye syndrome. J Pediatr 96:889-891

6. Cruse RP, DiMauro S, Towfighi J, Trevisan C 1984 Familial systemic carnitine deficiency. Arch Neurol 41:301-305 
7. Engel AG, Rebouche CJ, Wilson DM, Glasgow AM, Romshe CA, Cruse RP 1981 Primary systemic carnitine deficiency. II. Renal handling of carnitine. Neurology 31:819-825

8. Coates PM, Hale DE, Stanley CA, Glasgow AM 1984 Systemic carnitine deficiency simulating Reye syndrome. J Pediatr 105:679

9. Coates PM, Cortner JA, Hoffman GM, Brown SA 1979 Acid lipase activity of human lymphocytes. Biochim Biophys Acta 572:225-234

10. Frerman FE, Sabran JL, Taylor JL, Grossberg SE 1983 Leucine catabolism during the differentiation of 3T3-L1 cells. Expression of a mitochondrial enzyme system. J Biol Chem 258:7087-7093

11. Frerman FE, Goodman SI 1985 Fluorometric assay of acyl-CoA dehydrogenases in normal and mutant human fibroblasts. Biochem Med 33:38-44

12. Husain M, Steenkamp DJ 1983 Electron transfer flavoprotein from pig liver mitochondria. A simple purification and re-evaluation of some of the molecular properties. Biochem J 209:541-545

13. McKean MC, Beckmann JD, Frerman FE 1983 Subunit structure of electron transfer flavoprotein. J Biol Chem 258:1866-1870

14. Lowry OH, Rosebrough NJ, Farr AL, Randall RG 1951 Protein measurement with the Folin phenol reagent. J Biol Chem 193:265-275

15 Roe CR, Millington DS, Maltby DA, Bohan TP, Kahler SG, Chalmers RA 1985 Diagnostic and therapeutic implications of medium chain acylcarnitines in the medium chain acyl-CoA dehydrogenase deficiency. Pediatr Res (in press)

16. Howat AJ, Bennett MF, Vareind S, Shaw L 1984 Deficiency of medium-chain acylcoenzyme A dehydrogenase presenting as the sudden infant death syndrome. Br Med J 288:976

17. Lindstedt S, Norberg K, Steen G, Wahl E 1976 Structure of some aliphatic dicarboxylic acids found in the urine of an infant with congenital lactic acidosis. Clin Chem 22:1330-1338

18. Chalmers RA, Lawson AM, Whitelaw A, Purkiss P 1980 Twin siblings with a Reye's-like syndrome associated with an abnormal organic aciduria, hypoglycemia, diarrhea, and vomiting with close similarities to Jamaican vomiting sickness. Pediatr Res 14:1097-1103

19. Del Valle JA, Garcia MJ, Merinero B, Pérez-Cerdá C, Roman F, Jimenez A, Ugarte M, Martinez-Pardo M, Camarero C, Del Olmo R, Duran M, Wadman SK 1984 A new patient with dicarboxylic aciduria suggestive of me- dium-chain acyl-CoA dehydrogenase deficiency presenting as Reye's syndrome. J Inher Metab Dis 7:62-64

20. Truscott EJW, Hick L, Pullin C, Halpern B, Wilcken B, Griffith $H$, Silink M Kilham H, Grunseit F 1979 Dicarboxylic aciduria: the response to fasting. Clin Chim Acta 94:31-39

21. Naylor EW, Mosovich LL, Guthrie R, Evans JE, Tieckelmann H 1980 Intermittent non-ketotic dicarboxylic aciduria in two siblings with hypoglycemia: an apparent defect of $\beta$-oxidation of fatty acids. J Inher Metab Dis 3:19-24

22. Hale DE, Batshaw ML, Coates PM, Frerman FE Goodman SI, Singh I, Stanley CA 1985 Long-chain acyl coenzyme A dehydrogenase deficiency: an inherited cause of nonketotic hypoglycemia. Pediatr Res 19:666-670

23. Rhead WJ, Tanaka K 1980 Demonstration of a specific mitochondrial isovaleryl-CoA dehydrogenase deficiency in fibroblasts from patients with isovaleric acidemia. Proc Natl Acad Sci USA 77:580-583

24. Amendt BA, Rhead WJ 1984 A simple assay for medium chain acyl-CoA dehydrogenase (MCADH) activity in dicarboxylic aciduria (DCA) fibroblasts. Pediatr Res 18:290A(abstr)

25. Ikeda Y, Dabrowski C, Tanaka K 1983 Separation and properties of five distinct acyl-CoA dehydrogenases from rat liver. Identification of a new 2methyl branched chain acyl-CoA dehydrogenase. $J$ Biol Chem 258:10661076

26. Saudubray J-M, Coudé F-X, Demaugre F, Johnson C, Gibson KM, Nyhan WL 1982 Oxidation of fatty acids in cultured fibroblasts: a model system for the detection and study of defects in oxidation. Pediatr Res 16:877-881

27. Colle E, Mamer OA, Montgomery JA, Miller JD 1983 Episodic hypoglycemia with $\psi$-hydroxy fatty acid excretion. Pediatr Res 17:171-176

28. Gregersen N, Lauritzen R, Rasmussen K 1976 Suberylglycine excretion in the urine from a patient with dicarboxylic aciduria. Clin Chim Acta 70:417-425

29. Gregersen N, Rosleff F, Kolvraa S, Hobolth N, Rasmussen K, Lauritzen R 1980 Non-ketotic $\mathrm{C}_{6}-\mathrm{C}_{10}$-dicarboxylic aciduria:biochemical investigations of two cases. Clin Chim Acta 102:179-189

30. Gregersen N, K $\phi$ lvraa S, Rasmussen K, Mortensen PB, Divry P, David M, Hobolth N 1983 General (medium-chain) acyl-CoA dehydrogenase deficiency (non-ketotic dicarboxylic aciduria): quantitative urinary excretion pattern of 23 biologically significant organic acids in three cases. Clin Chim Acta 132:181-191

\title{
Aldosterone Metabolism and Transepithelial Potential Difference in Normal and Cystic Fibrosis Subjects
}

\author{
M. R. KNOWLES, J. T. GATZY, AND R. C. BOUCHER \\ Departments of Medicine and Pharmacology, University of North Carolina at Chapel Hill, \\ Chapel Hill, North Carolina 27514
}

\begin{abstract}
The transepithelial potential difference (PD) is raised across cystic fibrosis (CF) respiratory epithelia. This raised voltage reflects active sodium absorption across a relatively chloride impermeable membrane. Because relatively little is known about the regulation of the rate of sodium absorption across mammalian airways, we assessed the possible contribution of aldosterone to the PD in normal and CF respiratory epithelia. Aldosterone excretion in
\end{abstract}

Received December 14, 1983; accepted February 27, 1985.

Correspondence to M. R. Knowles, M.D., University of North Carolina, Department of Pulmonary Medicine, 724 Burnett-Womack Building $229 \mathrm{H}$, Chapel Hill, NC 27514.

Presented in part at the 23rd Annual Cystic Fibrosis Club Meeting, Washington, D.C., May 1982. Supported by NIH Grants HL00787, HL16674, and HL22924 Cystic Fibrosis Foundation RRDP Grant R002 4-01; and Clinical Research Unit Grant RR00040. R.C.B. is an established investigator of the American Heart Association. five CF patients was $12.2 \pm 0.9 \mu \mathrm{g} / 24 \mathrm{~h}$, a mean value not different from normal control subjects $(13.6 \pm 1.5 \mu \mathrm{g} / 24$ $h, n=5)$. Despite similar aldosterone excretion rates, nasal PD was more than 2-fold greater in the CF patients $(-53.6$ $\pm 6.4 \mathrm{mV}$ ) than normal subjects $(-21.3 \pm 1.4 \mathrm{mV})$. The effect of an aldosterone antagonist, spironolactone, on aldosterone excretion and nasal and rectal PD was evaluated in four CF patients and five normal subjects. During spironolactone administration, aldosterone excretion increased (2- to 4-fold) and rectal PD decreased in both groups. However, nasal PD was unchanged in each group $(C F=-52.1 \pm 4.3 \mathrm{mV}$ pre, $-53.6 \pm 1.4 \mathrm{mV}$ during; normal $=-21.2 \pm 3.1 \mathrm{mV}$ pre, $-21.6 \pm 3.2 \mathrm{mV}$ during). We conclude that neither increased aldosterone secretion rates nor organ sensitivity to aldosterone can account for the abnormally raised PD that characterizes the respira- 